\title{
Surgical treatment of Eagle's Syndrome through intraoral access: a case report and literature review
}

\author{
Rodrigo Cristhian Avelino Bezerra 1, Jonas Nogueira Ferreira Maciel Gusmão 1, 2, Bruno Frota Amora \\ Silva 1, Rodrigo Lemos Alves 1, Eliardo Silveira Santos 1, Roberto Dias Rêgo 1 \\ ${ }^{1}$ Department of Oral and Maxillofacial Surgery, Hospital Geral de Fortaleza, HGF, Fortaleza, Brazil. \\ ${ }^{2}$ Master degree in Morphofunctional Sciences at the Postgraduate Program in Morphofunctional \\ Sciences. Department of Morphology, Faculty of Medicine, Federal University of Ceará. Fortaleza, CE, \\ Brazil.
}

*Corresponding author: Jonas Nogueira Ferreira Maciel Gusmão. Ávila Goularte, n900 - Papicu. Zip Code: 60150160 - Ceará, CE, Brazil. Phone: +55 (85)9 8141-6401. E-mail: jonasnferreira@yahoo.com.br

Research Ethics Committee Approval (if necessary): Approved by the Hospital Geral de Fortaleza Ethics Committee (\#645.045).

Received on: Mar 22, 2021. Accepted on: Mar 22, 2021. Available online: Mar 31, 2021.

\begin{abstract}
The styloid process is a bone projection that originates in the tympanic portion of the temporal bone. The enlongation of the styloid process, or the ossification of the styloid process, can originate a series of symptoms such as dysphagia, odynophagia, facial pain, otalgia, headache, tinnitus and trismus, establishing the clinical picture of Eagle Syndrome. In this report, we present an important clinical case of adult patient diagnosed with Eagle's Syndrome who underwent surgery for reduction of the enlongated styloid process, by intraoral approach, added to a literature review study.
\end{abstract}

Keywords: Eagle's Syndrome; Surgery; Treatment.

\section{Introduction}

The styloid process is a bone projection that originates in the tympanic portion of the temporal bone. The elongation of the styloid process, or estilohioide ossification process, can cause a number of symptoms such as dysphagia, odynophagia, facial pain, ear pain, headache, tinnitus and trismus, which characterize clinical Eagle's syndrome [1].
The diagnosis of Eagle syndrome by analyzing the elongation of the styloid process, can be accomplished by analyzing skull radiography in profile, anteroposterior and oblique views, and also in the panoramic radiography, although the $\mathrm{CT}$ is considered the most efficient method for this assessment [12].

The treatment for this syndrome depends on the degree of discomfort and the benefit that the therapy can 
achieve, also considering the opportunity and the surgical need. [3]. For clinical cases of medium intensity, it is recommended drug control with injections of analgesic substances and/or corticosteroids. In cases of severe symptoms, the proposed treatment is surgical reduction of the styloid process, that can be performed in two ways: excision by intra or extraoral approach [3].

The choice of intraoral access for these cases has, as the main advantage for the patient, a shorter time of surgery, as well as a shorter hospitalization period, with less morbidity when compared to extraoral access [3]. In this premise, we present an important case report of an adult patient submitted to a surgical treatment of Eagle's syndrome by an intraoral approach

\section{Case report}

Male patient, 46 years old, brown, was admitted to a public hospital of reference in the state of Ceará / Brazil, with complaints of pain in the right cervical region when moving his neck, as well as when swallowing, referring the sensation of a foreign body presence in the throat. During the anamnesis, previous surgeries in the cervical region, such as tonsillectomy, were denied. The patient did not report drug allergies or systemic impairment. The patient reported that he was taking sporadic antidepressants (Bromazepan and Amitriptyline) without proper medical follow-up.
The extra-oral clinical examination did not reveal the presence of any altered clinical aspect. However, on intraoral examination (Figure 1A), palpation referred to pain in the region of the tonsillar pillar on the right side. It was requested CT examination in which evidenced enlongated styloid processes (Figures 1A and 1B), stablishing the diagnosis of Eagle's syndrome. The patient was instructed on the need for surgical treatment for a regression of his current pain condition, being referred for preoperative exams.

In the surgical approach, a partial removal of the right styloid process was planned through intraoral surgical access, under general anesthesia. During the surgery, a Boyle-Davis mouth gag was used, to assist in the operative field. The incision site was previously marked with Methylene Blue, followed by infiltration of anesthetic solution of Xylestesin $^{\circledR}$ in the region. The incision was made with a \#15 blade scalpel through the mucosal and muscular planes, until the styloid process visualization. The incision was followed by cautious detachment of the region with Molt elevator.

The styloid process (Figure 1D) was apprehended with a Kelly forceps, and then fractured at the desired height, with the same instrument. After the removal of the styloid's segment (Figure $1 \mathrm{E})$, hemostasis was reviewed, followed by suture with simple stitches, by tissue planes, using 3-0 and 4-0 Vicryl ${ }^{\circledR}$. No complications were recorded in the 
immediate or late postoperative period. Upon postoperative Ct scan (Figure $1 \mathrm{~F}$ ), the reduction of the right styloid process was evidenced, when compared with the preoperative image of the same region. After six months of follow-up, the patient was reassessed and total regression of the pain was identified and there was no sensation of a foreign body when swallowing.
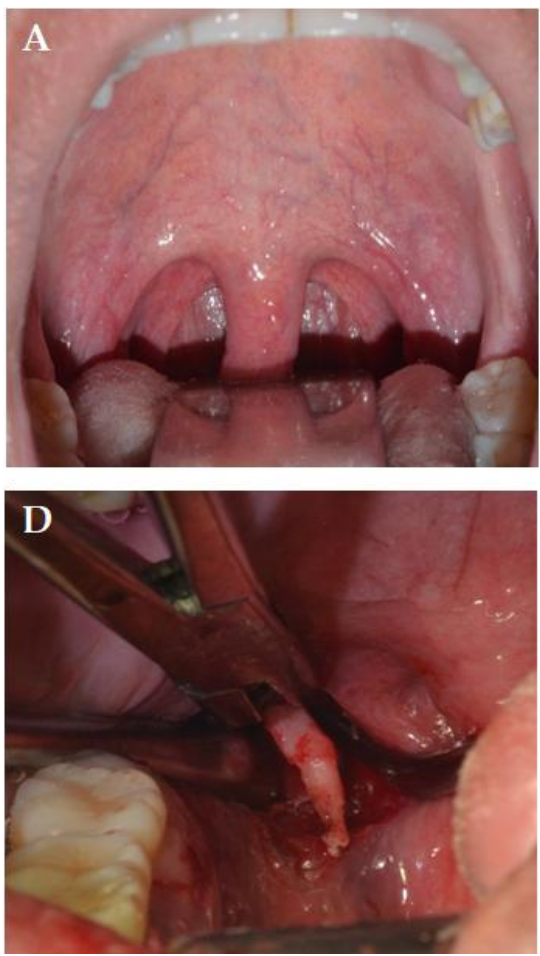
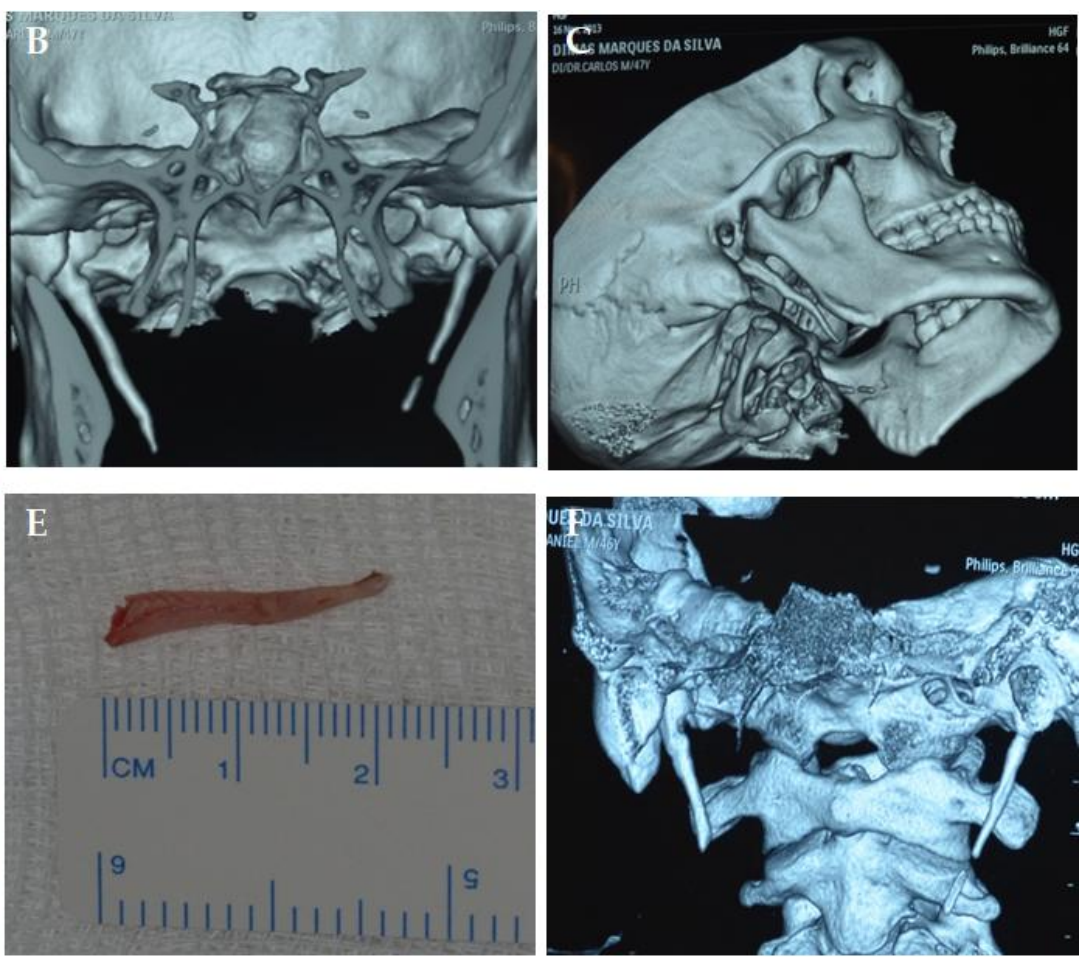

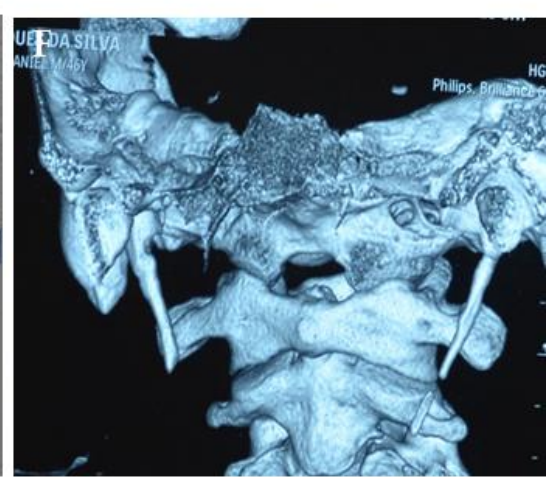

Figure 1. A. Intra-oral view of the patient. Coronal (B) and lateral (C) view of the skull by computed tomography showing bilateral enlargement of the styloid. D. Intraoperative view showing excision of the styloid process. E. Specimen of postsurgical styloid process. E. Coronal view of the skull by post-surgical computed tomography.

Table 1. Reported cases of patients with Eagle's Syndrome with your clinical presentation.

\begin{tabular}{lclc}
\multicolumn{1}{c}{ Author, year } & $\begin{array}{c}\text { Number of } \\
\text { cases }\end{array}$ & Description & References \\
\hline Gervickas, 2004 & 30 & $\begin{array}{l}\text { Use of surgical treatment for the treatment of } \\
\text { Eagle Syndrome }\end{array}$ & {$[8]$} \\
Peng, 2011 & 22 & $\begin{array}{l}\text { Use of surgical treatment by extra buccal access } \\
\text { for the treatment of Eagle Syndrome }\end{array}$ & {$[7]$} \\
Sadaksharam, 2012 & 1 & $\begin{array}{l}\text { Use of surgical treatment with intraoral approach } \\
\text { for the treatment of Eagle Syndrome }\end{array}$ \\
\hline
\end{tabular}


Surgical treatement of Eagle's Syndrome through intraoral access

$\begin{array}{lll}\text { Scheller, } 2014 & 6 & \begin{array}{l}\text { Use of surgical treatment with intraoral approach } \\ \text { for the treatment of Eagle Syndrome }\end{array} \\ \text { Matsumoto, } 2012 & 1 & \begin{array}{l}\text { Use of surgical treatment with intraoral approach } \\ \text { for the treatment of Eagle Syndrome }\end{array}\end{array}$

[10]

\section{Discussion and Conclusion}

The classic Eagle's syndrome presents with continuous pain in the pharynx that worsens during swallowing and often radiates to the ipsilateral ear. The patient reports intense salivation, discomfort, choking on swallowing and impression of a foreign body in the throat. The pain of the patient with Eagle's Syndrome can be attributed to the healing process present after tonsillectomy or cervical trauma and can occur at any age. Pain is also believed to be due to distortion and compression of the sensory and motor nerve endings of cranial pairs V, VII, IX and $\mathrm{X}$ [3].

For diagnostic purposes, the symptoms of Eagle's syndrome must be correlated with the radiographic findings, in addition to the clinical examination, palpating the tip of the process at the level of the tonsillar fossa and obtaining relief of symptoms by infiltrating lidocaine in the region of the tonsillar fossa [3].

The forms of treatment proposed in the scientific literature vary from conservative to surgical treatment, however, most authors agree that surgical treatment is the only effective treatment. As surgical treatments, both intraoral and extraoral access always present their advantages and disadvantages in relation to the other [4].

The intraoral approach technique has the advantages of a shorter procedure time, absence of cutaneous scarring, safer and simpler method, shorter recovery period and, in certain cases, allows it to be performed in an outpatient setting. However, possible complications must be taken into account, such as the possibility of infection of the deep spaces of the neck, need for ligature of the carotid arteries, osteomyelitis, damage to nerves V, VII, IX, X, XI or its branches, hemorrhage, emphysema, inadequate access for very long styloid processes (with or without ligament ossification) and dysphagia [4].

Regarding extraoral surgical approaches, it is emphasized that several possibilities of techniques are described, being defended by the possibility of better exposure of the surgical field, especially of the carotid arteries, presenting a lower risk of bacterial contamination and less blood loss. As disadvantages, in addition to the presence of a skin scar, the increase in the procedure time, the need for general anesthesia and the possibility of 
transient paresthesia of the great auricular nerve can be highlighted [4].

On these topics, about our literature review (Table 1), Casale and colleagues [5] demonstrated the possibility of using conservative treatment for Eagle's Syndrome, especially for patients who refuse the surgical approach. It was reported in that study that, from the use of infiltrations with non-steroidal antiinflammatory drugs (NSAIDs) by patients with Eagle's syndrome, patients obtained satisfactory results in a 6month follow-up without recurrence of pain symptoms [5].

In the study by Németh and collaborators [6], the use of extraoral access is justified, claiming that it is preferable because of the better visualization of the operative field, as it is easier to locate the extension of the hyoid bone, and, if necessary, removal is facilitated. The easy access to the external carotid artery, with this approach, provides rapid hemostasis, if necessary. Another advantage is that, by not exposing the surgical site to oral flora, the risk of postoperative infection is reduced, such as the possibility of forming a parapharyngeal abscess [6].

In addition, in a series of 22 patients with Eagle's syndrome who underwent surgical treatment with extra-oral access, Peng et al. [7] identified that 19 patients reported absence of pain symptoms after an average of 17 months of follow-up, with no association of evident scar or paresthesia in the region. On the other hand, some authors reinforce that intraoral access for the surgical treatment of Eagle's Syndrome is the best and safest choice. In the study by Gervickas and collaborators [8], a total of 30 patients with Eagle's syndrome who underwent surgical therapeutic approach were evaluated, in which it was concluded that this treatment is the most effective in resolving symptoms after 5 years of follow-up [8].

Sadaksharam and colleagues [9] reported a case of a 24-year-old patient with bilateral pain symptoms. Surgical treatment was performed through the intraoral access on the right side after tonsillectomy and extra-oral access on the left side, with no painful symptoms being evidenced on both sides [9].

In a retrospective study of 6 patients with Eagle's syndrome with bilateral pain symptoms operated by intraoral access, it was identified that the mean time of surgery was 29 minutes, and after 1 year of follow-up, 5 patients had total remission of symptoms. and 1 showed partial remission [10].

Matsumoto et al. [11] reported that a patient was operated through intraoral access with previous ipsilateral tonsillectomy, using an endoscope as an auxiliary mean. In this report, it was possible to identify the noble structures during the procedure, without complications at the surgical site, 
allowing oral feeding in the postoperative period of 1 day [11].

From the scientific survey presented and the case report now described, it was possible to conclude that the use of intraoral surgical access for the treatment of Eagle's Syndrome is a viable option as long as the surgeon is aware of its complications, thus providing a faster surgery and an absence of anesthetically visible scars.

\section{References}

[1] Tiago RSL, Marques Filho MF, Maia CAS, Santos OFS. Síndrome de Eagle: avaliação do tratamento cirúrgico. Revista Brasileira de Otorrinolaringologia. 2002, 68(2), 196$201 . \quad$ doi: 10.1590/S003472992002000200007 .

[2] Rosa RR, Kohatsu LI, Moraes LC, Medici Filho E, Moraes MEL, Castilho JCM. Síndrome de Eagle: revisão da literatura sobre variações, diagnóstico e tratamento. Revista de Odontologia da Universidade Cidade de São Paulo. 2008, 20(3): 288-94.

[3] Auricchio R, Casteleins WA, Motter A, Dias DF, Simões JC, Driessen A. Síndrome de Eagle: relato de caso. Rev. Med. Res. 2012, 14(3):205-209.

[4] Carlini JL, Strujak G, Biron C, Gebert AO, Romanowisk M. Síndrome de Eagle: relato de caso tratado por abordagem intraoral e revisão de literatura. Ver. Bra. De Cir. Buco-maxilofacial. 2010,10(1):77-82.

[5] Mortellaro C, Biancucci P, Picciolo G, Vercellino V. Eagle's syndrome: importance of a corrected diagnosis and adequate surgical treatment. J Craniofac Surg. 2002 Nov;13(6):755-8. doi: 10.1097/00001665-200211000-00007.

[6] Nemeth O, Csaki G, Csado K, Kivovics C. Case report of a 27 year old patient suffering from Eagle's syndrome.OHDMBSC.2010;9(3).

[7] Peng GG, Chen WL, Wu JW, Pan JY. Eagle's syndrome treated with dissection of the styloid process via an extraoral approach combined with antidepressants. Chin J Dent Res. 2011;14(1):37-40.

[8] Gervickas A, Kubilius R, Sabalys G. Clinic, Diagnostics and Treatment Pecularities of Eagle's Syndrome. Stomatologija, Baltic Dental and Maxillofacial Journal. 2004, 6:11-13.

[9] Sadaksharam J, Singh K. Stylocarotid syndrome: An unsual case report. Contemp Clin Dent. 2012;3: 503-6.

[10] Scheller K, Eckert AW, Scheller C. Transoral, retromolar, para-tonsillar approach to the styloid process in 6 patients with Eagle's syndrome. Med Oral Patol Oral Cir Bucal. 2014 Jan 1;19(1):e61-6.

doi: 10.4317/medoral.18749.

[11] Matsumoto F, Kase K, Kasai M, Komatsu H, Okizaki T, Ikeda K. Endoscopy-assisted transoral resection of the styloid process in Eagle's syndrome. Case report. Head Face Med. 2012 Jul 30;8:21. doi: 10.1186/1746-160X8-21. 
Conflict of interest: The author declares no conflicts of interest.

Acknowledgements: None.

Funding: None.

How to cite this article: Bezerra RCA, Gusmão JNFM, Silva BFA, Alves RL, Santos ES, Rêgo RD. Surgical treatment of Eagle's Syndrome through intraoral access: a case report and literature review. Brazilian Journal of Case Reports. 2021Jan-Mar;01(1):15-21. 